\title{
Robustness of steel building structures following a column loss
}

\author{
Clara HUVELLE \\ Civil Engineer, PhD student \\ ULg, dept ArGenCo \\ Liege, Belgium \\ clara.huvelle@ulg.ac.be
}

\author{
Jean-Pierre JASPART \\ Professor \\ ULg, dept ArGenCo \\ Liege, Belgium \\ jean-pierre.jaspart@ulg.ac.be
}

\author{
Jean-François DEMONCEAU \\ Associate Professor \\ ULg, dept ArGenCo \\ Liege, Belgium \\ ifdemonceau@ulg.ac.be
}

\section{Summary \\ The present paper gives a global overview on recent developments performed at Liège University in the field of robustness of building structures for the specific scenario "loss of a column". In particular, the static non-linear response of a steel building structure following a column loss will be first presented and then, a global overview of some recent achievements and ongoing researches will be given with the global strategy aiming at deriving design requirements for practitioners.}

Keywords: robustness, loss of a column, non-linear response, design requirements

\section{Introduction}

Recent events such as natural catastrophes or terrorism attacks have highlighted the necessity to ensure the structural integrity of buildings under an exceptional event. According to Eurocodes and some other national design codes, the structural integrity of civil engineering structures should be ensured through appropriate measures but, in most cases, no precise practical guidelines on how to achieve this goal are provided. At Liège University, the exceptional event "loss of a column" in a building structure is under investigation, using experimental, numerical and analytical approaches with the final objective to propose design requirements to ensure an appropriate robustness under the considered scenario.

Through first developments, an analytical procedure has been developed to check the robustness of steel or composite plane frames. For sake of simplicity, these first studies have been conducted on the assumption that the dynamic effects linked to the column loss were limited and could therefore be neglected.

More recently, complementary works ([1] and [2]) have been carried out with the objective to address the dynamic effects and a method has been developed that can predict the dynamic behaviour of the frame. The input data of this method are:

- the static response of the frame

- the ratio between the time of failure of the column $t_{r}$ and the fundamental period of the frame $T$

These dynamic developments are not addressed in the present paper, but more information can be found in [2]. The present paper will mainly focus on the static behaviour of a frame losing a column. Firstly, the global strategy aiming at deriving design requirements will be presented and then a global overview of some recent achievements and ongoing researches in the field of robustness will be given.

\section{Static behaviour of $2 \mathrm{D}$ frames following a column loss}

\subsection{Introduction and general concepts}

The present section describes the global strategy adopted at Liège University. The presented study is dedicated to frames only composed of columns and beams; the possible beneficial effect of the slab is presently neglected in the developments. The investigations performed at Liège University in the field of "robustness of structures" are mainly dedicated to the exceptional scenario "loss of a column" in a steel or steel-concrete composite building structure. Under many exceptional actions (explosions, impacts ...), dynamic effects may play an important role. However, it is first assumed that the column loss does not induce such dynamic effects. The main objective of the conducted 
investigations is to derive guidelines aiming at ensuring an appropriate behaviour of the structure for the considered scenario. To achieve this goal, simplified analytical procedures are developed to predict the response of the structure further to a column loss; this allows to clearly identify how each structural parameter may influence the structural behaviour.

Phase 1

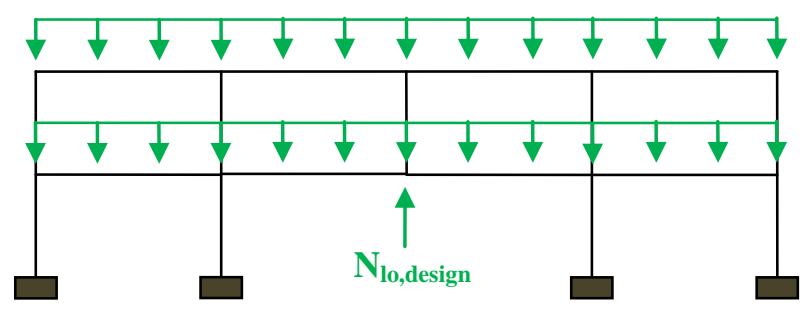

Phase 2: plastic mechanism

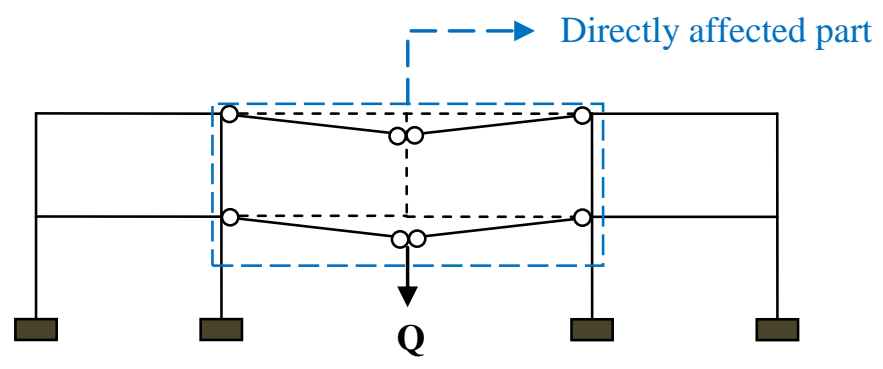

Phase 3: catenary actions

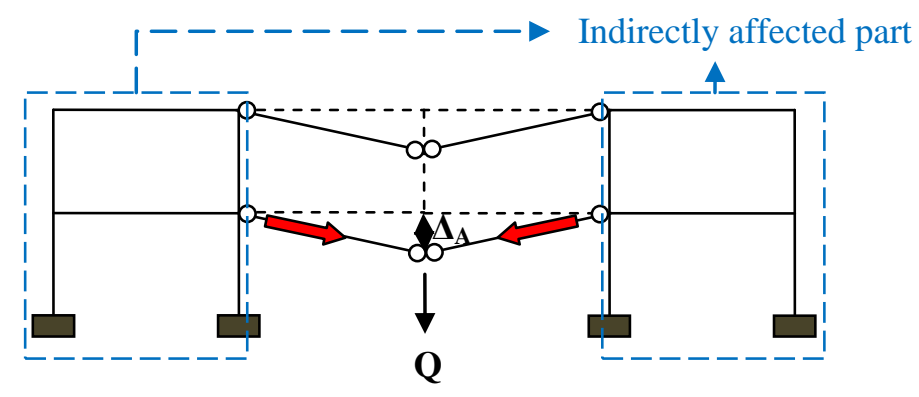

Fig. 1: Phases during a column loss in a frame
A building structure losing a column can be divided in two main parts, as illustrated in Fig. 1: the directly affected part that represents the part of the building which is directly affected by the column loss, i.e. the beams, the columns and the beam-tocolumn joints above the failing column; and the indirectly affected part which consists in the rest of the structure. The indirectly affected part is affected by the loads developing within the directly affected part and also influences the development of these loads.

The objective of the studies performed at Liège University is to be able to predict the evolution of the vertical displacement of point "A" $\Delta_{A}$ (i.e. at the top of the lost column) according to $N_{l o}$, the compression force in the lost column that decreases as the column disappears. The loss of a column in a structure can be simulated by applying a force " $Q$ " downwards at the top of the failing column (Fig. 1). Accordingly, if the compression load in the critical column is equal to $N_{l o, d e s i g n}$ before it starts failing (Fig. 1), the column is considered as fully lost when $Q$ is equal to $N_{l o, d e s i g n}$ $\left(N_{l o}=N_{l o, d e s i g n}-Q\right)$. Knowing this value of $\Delta_{A}$ when $Q$ is equal to $N_{l o, d e s i g n}$ it is possible to determine the requests in terms of deformation capacity for the structural elements and the load distribution within the structure and so, to check the structural resistance and stability.

When a frame losses one of its column, different phases are successively met (Fig. 1). The first phase is the "normal" loading condition of the frame: $N_{l o}$ is equal to its conventional design value which is $N_{l o, d e s i g n}$ and $Q$ equals 0 . The column begins to disappear at the beginning of phase 2 ( $Q$ increases and $N_{l o}$ decreases). During this second phase, a plastic mechanism forms in the directly affected part. When this plastic mechanism is totally developed, this is the beginning of phase 3: as a plastic mechanism has formed in the directly affected part, the first order stiffness of the structure is equal to zero and so, large displacements occur. Due to these large displacements, significant membrane forces develop in the beams of the directly affected part, that are associated to second order effects. The column is completely removed when the compression force in the column $N_{l o}$ is equal to zero, which means $Q=N_{l o, d e s i g n}$.

It is only possible to reach this stage if (i) the loads that are reported from the directly affected part to the indirectly affected part do not induce failures (for instance, buckling of columns or development of a global plastic mechanism in the indirectly affected part) and if (ii) the different structural elements have a sufficient ductility to reach the vertical displacement corresponding to the total disappearance of the column. 


\subsection{Definition of a substructure}

Predicting the behaviour of the structure during Phase 1 and 2 is easy as usual analysis methods can be used. However, during Phase 3, the analysis of the frame and the prediction of its response become complex as significant second order effects are developing. The objective with the developed analytical procedure is to be able to predict the response of the frame during Phase 3 .

In previous developments conducted in Liege University (and in particular by Demonceau [3]), the substructure that was defined to study the phase 3 was composed only with the lower beam of the directly affected part, i.e. the beams just above lost column (Fig. 2). This substructure was studied according to a rigid plastic analysis because the aim was to focus on phase 3 . The rest of the structure (i.e. the indirectly affected part) was represented in this substructure by one horizontal spring. Luu [4] developed a method to analytically compute the properties of this spring (i.e. its stiffness and its resistance). However, the method developed by Luu and Demonceau is only valid if the compression force in the column just above the lost one remains constant during the all duration of phase 3, which is not always the case, as it has been demonstrated in [5] and [6]. This can be understood by comparing the behaviour of two structures as shown in Fig. 3. In the frame on the left, the indirectly affected part sags on the directly affected one, and the compression force in the column above the lost one can either increase or remain constant. In the frame on the right, no horizontal displacement is allowed, and the upper stories help the lower beam to support the loss of the column. In this case, the effort in the upper column may even go into tension.
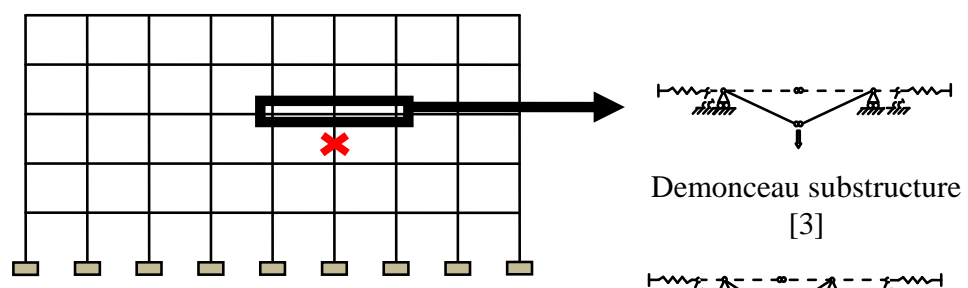

Demonceau substructure [3]

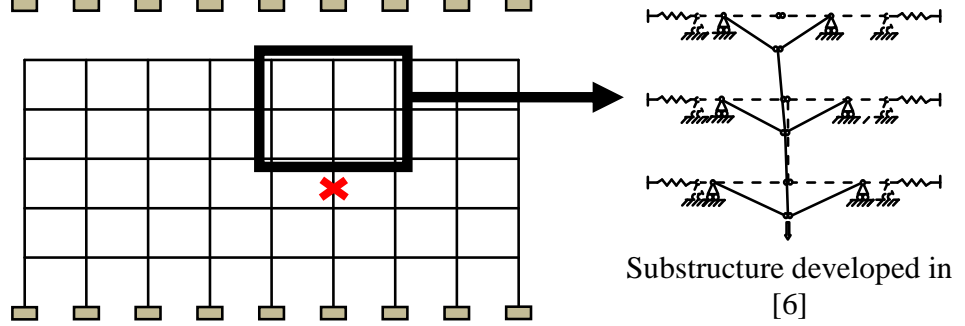

Fig. 2: Demonceau substructure [3] and substructure developed in [6]
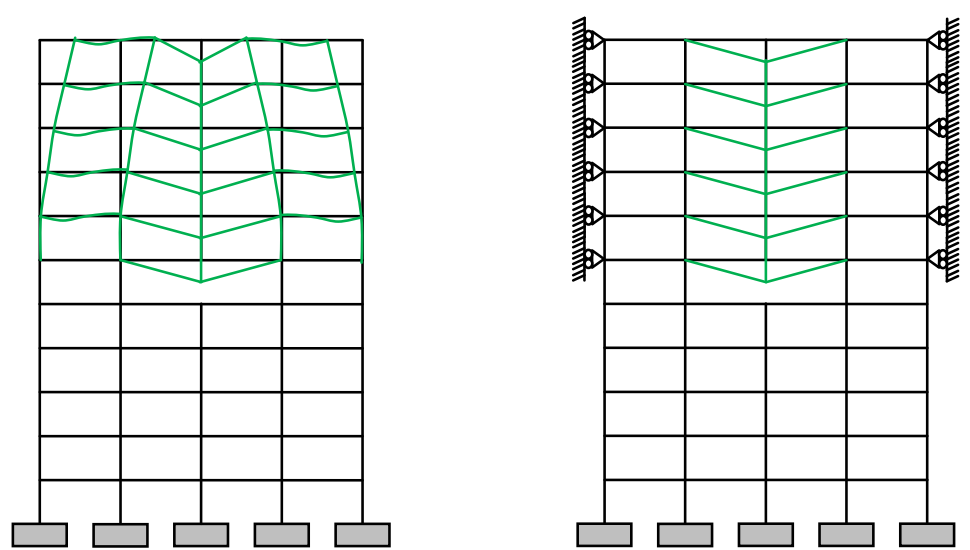

Fig. 3: Variation in the compression force in the upper columns
These considerations have brought into light important coupling effects between the stories of the directly affected part, and also between the directly affected part and the indirectly affected part.

Actually, it is just as if a vertical spring was missing in the substructure defined by Demonceau (Fig. 2), i.e. a spring that could simulate the effect of the upper stories of the directly affected part.

To take into account these new coupling effects, a new substructure has been developed in [6]. As can be seen in Fig. 2, this substructure is composed of all the stories of the directly affected part. The indirectly affected part is replaced by horizontal springs at each storey. These springs are coupled to each other, because the horizontal displacement at one storey does not only depend on the horizontal force acting at this level but also depends on the horizontal forces acting at the other stories. As the developed method is used to predict the structural response during Phase 3, this substructure is studied through a second-order rigid-plastic analysis. It has been demonstrated in [6] that the so-defined substructure is able to reflect with a very good agreement the global response of a frame during Phase 3. 


\subsection{Analytical model to predict the substructure response}

Within the present section, the equations needed to predict the so-defined substructure response during Phase 3 are presented. These equations are related to two distinct parts of the frame as defined in Fig. 1: the directly affected part and the indirectly affected part. This results in different "blocks" connected to each other, with compatibility equations between them (Fig. 4): block 1 represents one storey of the directly affected part and block 2 is the indirectly affected part.

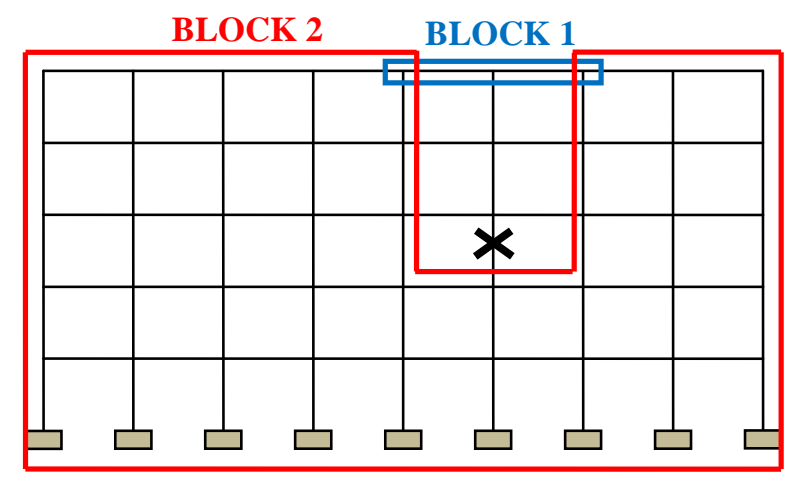

BLOCK 1

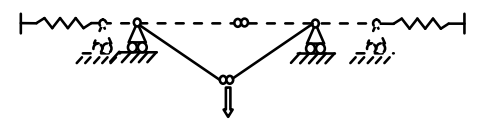

BLOCK 2

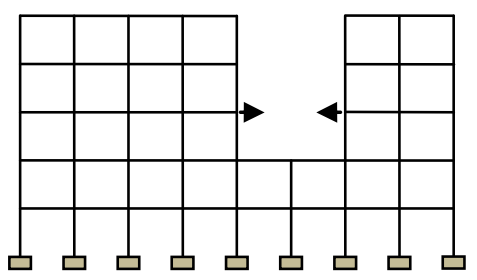

Fig. 4: Definition of blocks

First, the equations for the block 1 will be considered. For one storey, 10 equations can be derived considering the static theorem (i.e. force equilibrium - eqs (1) \& (2) - Fig. 6), the kinematic theorem (i.e. compatibility of displacements - eqs (3) to (6) - Fig. 5), the properties of the yielded sections (development of M-N interaction - eqs (7) \& (8)) and the plastic elongation of the yielded beams (eqs (9) \& (10)).

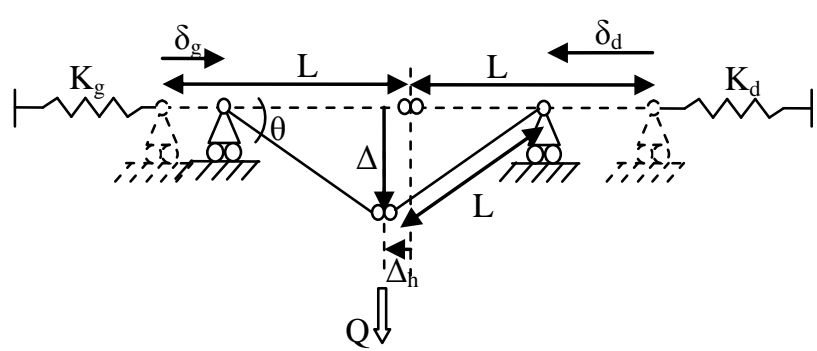

Fig. 5: Internal forces in the substructure

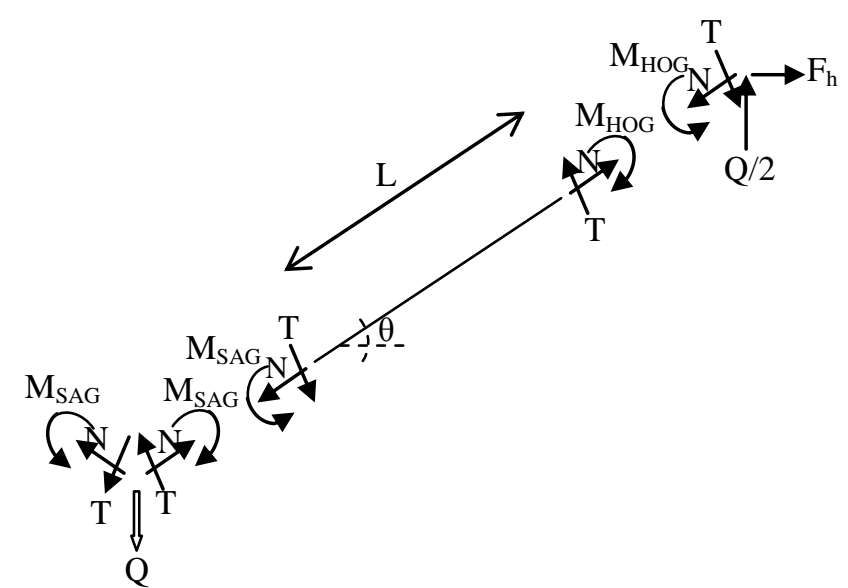

$$
\begin{aligned}
& Q=2 N \sin \theta+2 \frac{M_{H O G}-M_{S A G}}{L} \cos \theta \\
& N=F_{h} \cos \theta+\frac{Q}{2} \sin \theta \\
& \tan \theta=\frac{\Delta}{L_{0}-\frac{\delta_{d}+\delta_{g}}{2}} \\
& L=\sqrt{\left(L_{0}-\frac{\delta_{d}+\delta_{g}}{2}\right)^{2}+\Delta^{2}} \\
& L=L_{0}+\delta_{N, S A G}(N)+\delta_{N, H O G}(N) \\
& \Delta_{h}=\frac{\delta_{d}-\delta_{g}}{2} \\
& M_{H O G}=f(N) \\
& M_{S A G}=f(N) \\
& \delta_{N, H O G}=f(N) \\
& \delta_{N, S A G}=f(N)
\end{aligned}
$$

Fig. 6: Substructure: consideration of one storey 
In case the number of stories of the directly affected part is equal to $n_{s t}$, block 1 has to be considered $n_{s t}$ times. All the 10 expressed equations are of course still valid for each block, and compatibility equations between these blocks have to be added to the model:

$$
\begin{aligned}
& Q=Q_{1}+Q_{2}+\ldots+Q_{n_{s t}} \\
& \Delta=\Delta_{1}=\Delta_{2}=\ldots=\Delta_{n_{s t}}
\end{aligned}
$$

In the equations (11) and (12), $Q$ is the total force applied to the substructure simulating the loss of the column, while $Q_{i}$ is the part of that force supported by the storey n " $\mathrm{i}$ ". In terms of displacements, all the stories have the same vertical displacement, equal to $\Delta$ (i.e. it is assumed that the columns elongation between the floors can be neglected). These compatibility equations between the stories represent $n_{s t}+1$ equations.

The equations for block 2, i.e. the equations coming from the indirectly affected part are displacement compatibility equations. Indeed, the displacements $\delta_{g}$ and $\delta_{d}$ at each storey are common to the directly affected part and to the indirectly affected one. So, the following equations can be written, for a number of stories equal to $n_{s t}$ :

$$
\begin{aligned}
& \delta_{g, i}=\sum_{j=1}^{n_{s t}} s_{g, j, i} F_{j} \\
& \delta_{d, i}=\sum_{j=1}^{n_{s t}} s_{d, j, i} F_{j}
\end{aligned}
$$

This represents a total of $2 n_{s t}$ equations. These equations express the presence of the horizontal springs in the substructure, taking into account the fact that these springs are coupled to each other. The values of $s_{g, i j}$ or $s_{d, i j}$, respectively for the left and right parts, are the terms of the "lateral stiffness matrix" of the indirectly affected part, and they are easily determined through first order elastic analysis, assuming that the indirectly affected part remains in the elastic domain during the column loss. To determine the terms $s_{g, 1 j}$ and $s_{d, 1 j}$ a force $\mathrm{F}=1 \mathrm{kN}$ is applied at the first storey of the directly affected part (Fig. 7 (a)) in a structure from which the directly affected part has been removed. The terms $s_{g, 1 j}$ and $s_{d, 1 j}$ are the horizontal displacements of the extremities of storey " $\mathrm{j}$ " of the directly affected part under this solicitation. In the same way, to determine the terms $s_{g, 2 i}$ and $s_{d, 2}$, a force $\mathrm{F}=1 \mathrm{kN}$ has to be applied at the second storey of the directly affected part (Fig. 7 (b)). And so on for the other $s_{g, i j}$ or $s_{d, i j}$ terms.

Loads

Displacements

(a)

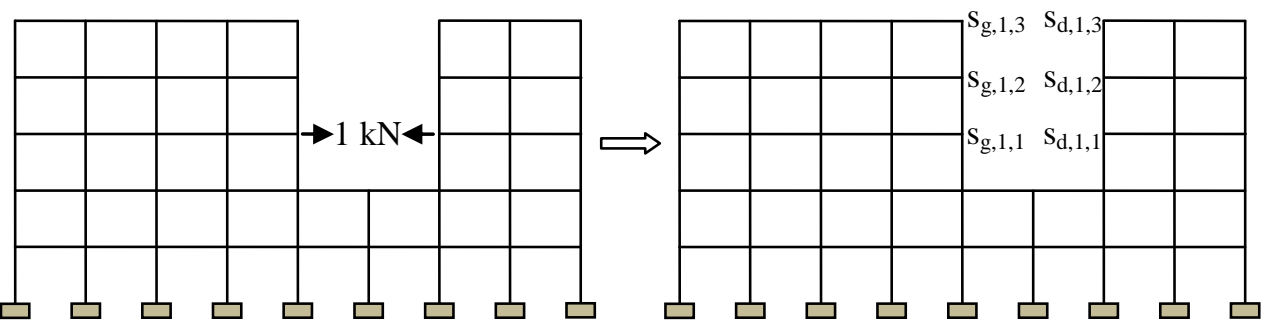

Loads

Displacements

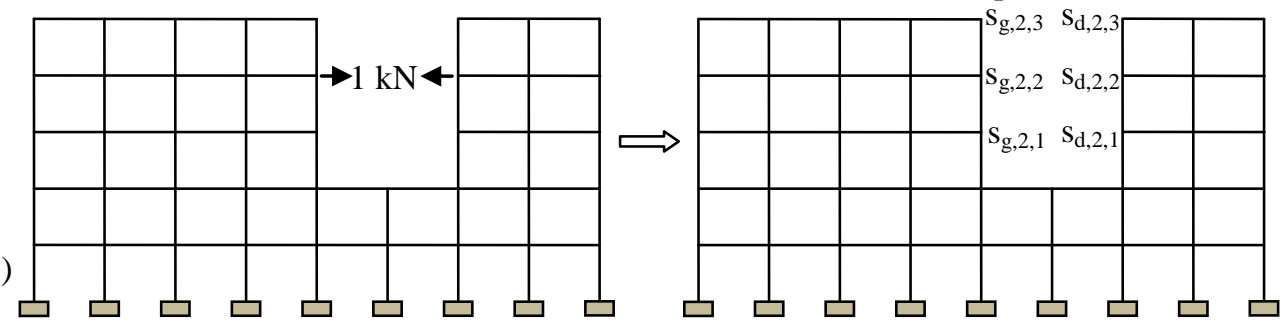

Fig. 7: Determination of $s_{i j}$ terms 
Finally, for a given value of $\Delta$, and since the number of unknowns is equal to the number of equations (see Table 1), this equations system can be solved (using appropriate software such as MATLAB, MATHEMATICA, MATCAD...) and the corresponding $Q$ can finally be obtained. The inputs of the model are the following:

- $L_{0}$, the initial length of the beams

- The lateral stiffness matrix of the indirectly affected part (the terms $s_{g, i j}$ and $s_{d, i j}$ )

- The M-N interaction laws, in both hogging and sagging. If the hinge occurs in the beam, it corresponds to the $\mathrm{M}-\mathrm{N}$ resistant interaction curve of a steel or composite section. If the hinge occurs in the joint, then it corresponds to M-N resistant interaction curve of the joint; analytical methods to predict the latter for steel joints [7] and composite joints [3] have been developed and validated at Liège University.

- The laws between $\delta_{N, S A G}-\delta_{N, H O G}$ and $\mathrm{N}$, reflecting the plastic elongation of the plastic hinges when membrane forces are developing. They are assumed to be linear (as highlighted through numerical simulations), so that $K_{N} \delta_{N}=N$. These laws cannot be, at this stage of the developments, determined analytically. The development of an analytical procedure for the prediction of this law constitutes a perspective to the presented developments (presently under investigation at Liège University).

Table 1: Summary of unknowns and equations

\begin{tabular}{|c|c|c|c|}
\hline \multicolumn{2}{|c|}{ Unknowns } & \multicolumn{2}{|l|}{ Equations } \\
\hline$Q$ & 1 & $\Delta=$ fixed value & 1 \\
\hline$\Delta$ & 1 & $Q=Q_{1}+Q_{2}+\ldots+Q_{n_{s t}}$ & 1 \\
\hline$Q_{i}$ & $n_{s t}$ & $\Delta=\Delta_{1}=\Delta_{2}=\ldots=\Delta_{n_{s t}}$ & $n_{s t}$ \\
\hline$N_{i}$ & $n_{s t}$ & $Q_{i}=2 N_{i} \sin \theta_{i}+2 \frac{M_{H O G, i}-M_{S A G, i}}{L_{i}} \cos \theta_{i}$ & $n_{s t}$ \\
\hline$M_{H O G, i}$ & $n_{s t}$ & $N_{i}=F_{h, i} \cos \theta_{i}+\frac{Q_{i}}{2} \sin \theta_{i}$ & $n_{s t}$ \\
\hline$M_{S A G, i}$ & $n_{s t}$ & $\tan \theta_{i}=\frac{\Delta_{i}}{L_{0}-\frac{\delta_{d, i}+\delta_{g, i}}{2}}$ & $n_{s t}$ \\
\hline$\delta_{N, H O G, i}$ & $n_{s t}$ & $L_{i}=\sqrt{\left(L_{0}-\frac{\delta_{d, i}+\delta_{g, i}}{2}\right)^{2}+\Delta_{i}^{2}}$ & $n_{s t}$ \\
\hline$\delta_{N, S A G, i}$ & $n_{s t}$ & $L_{i}=L_{0}+\delta_{N, S A G, i}\left(N_{i}\right)+\delta_{N, H O G, i}\left(N_{i}\right)$ & $n_{s t}$ \\
\hline$\theta_{i}$ & $n_{s t}$ & $\Delta_{h, i}=\frac{\delta_{d, i}-\delta_{g, i}}{2}$ & $n_{s t}$ \\
\hline$F_{h, i}$ & $n_{s t}$ & $M_{H O G, i}=f\left(N_{i}\right)$ & $n_{s t}$ \\
\hline$L_{i}$ & $n_{s t}$ & $M_{S A G, i}=f\left(N_{i}\right)$ & $n_{s t}$ \\
\hline$\Delta_{h, i}$ & $n_{s t}$ & $\delta_{N, H O G, i}=f\left(N_{i}\right)$ & $n_{s t}$ \\
\hline$\Delta_{i}$ & $n_{s t}$ & $\delta_{N, S A G, i}=f\left(N_{i}\right)$ & $n_{s t}$ \\
\hline$\delta_{g, i}$ & $n_{s t}$ & $\delta_{g, i}=\sum_{i=1}^{n_{s t}} s_{g, j, i} F_{j}$ & $n_{s t}$ \\
\hline$\delta_{d, i}$ & $n_{s t}$ & $\delta_{d, i}=\sum^{n_{s t}} s_{d, j, i} F_{j}$ & $n_{s t}$ \\
\hline TOTAL $=$ & $13 n_{s t}+2$ & TOTAL $=$ & $13 n_{s t}+2$ \\
\hline
\end{tabular}




\section{Conclusion}

At Liège University, the exceptional scenario "loss of a column" in a building structure has been under investigation for a few years with the final objective to propose design requirements to ensure an appropriate robustness of structures under the considered scenario.

The present paper gives a global overview of the adopted strategy to deal with this scenario, of the achievements in this field so far and of the ongoing research activities. In particular, simplified analytical methods have been developed to predict the static response of 2D steel and composite frames further to a column loss. The developed method allows predicting the response of a structure following a column loss using quite simple tools, thus avoiding the use of complex finite element simulations and constitutes the starting point for the development of design recommendations.

A global approach was first developed for steel and composite structures but may be applied to other typologies of structures, as given in Fig. 8. Investigations have also been initiated to take the $3 \mathrm{D}$ behaviour [5] and the dynamic effects [1] into account as reflected in Fig. 8. The objective at the end is to have Fig. 8 fully completed with " $\mathrm{D}$ " which would mean that design recommendations have been derived for most typologies of structures and are founded on the same global approach.

\begin{tabular}{l}
\begin{tabular}{|l|c|c|c|c|c|}
\hline $\begin{array}{l}\text { Design } \\
\text { recommendations }\end{array}$ & TBD & TBD & TBD & TBD & TBD \\
\hline Dynamic effects & I & TBD & TBD & TBD & TBD \\
\hline 3D behaviour & I & I & TBD & TBD & TBD \\
\hline 2D behaviour & D & D & TBD & TBD & TBD \\
\hline Global approach & D & D & D & D & D \\
\hline & $\begin{array}{c}\text { Steel } \\
\text { structures }\end{array}$ & $\begin{array}{c}\text { Composite } \\
\text { structures }\end{array}$ & $\begin{array}{c}\text { Concrete } \\
\text { structures }\end{array}$ & $\begin{array}{c}\text { Timber } \\
\text { structures }\end{array}$ & $\begin{array}{l}\text { Masonry } \\
\text { structures }\end{array}$ \\
\hline
\end{tabular} \\
\hline
\end{tabular}

Fig. 8: Steps to be crossed to derive design recommendations

\section{4. $\quad$ References}

[1] COMELIAU L., "Effects of the dynamic behaviour of steel structures further to a column loss (in French)", Master thesis presented at Liege University, 2009 (freely downloadable at http://hdl.handle.net/2268/32284).

[2] COMELIAU L., ROSSI B., DEMONCEAU J.-F., "Robustness of steel and composite buildings suffering the dynamic loss of a column", Structural Engineering International (to be published)

[3] DEMONCEAU J.-F., "Steel and composite building frames: sway response under conventional loading and development of membrane effects in beams further to an exceptional action", PhD thesis presented at Liege University, 2008 (freely downloadable at http://orbi.ulg.ac.be/handle/2268/2740).

[4] LUU H.N.N., "Structural response of steel and composite building frames further to an impact leading to the loss of a column", PhD thesis presented at Liege University, 2008 (freely downloadable at http://bictel.ulg.ac.be/ETD-db/collection/available/ULgetd01212009-095305/).

[5] LEMAIRE F., "Study of the 3D behaviour of steel and composite structures further to a column loss (in French)", Master thesis presented at Liege University, 2010. 
[6] HUVELLE C., "Contribution to the study of the robustness of building structures. Effect of the progressive yielding of the "indirectly affected part (in French)", Master Thesis presented at Liege University, 2011 (freely downloadable at http://hdl.handle.net/2268/127083).

[7] CERFONTAINE F., "Study of the interaction between bending moment and axial force in bolted joints (in French)", PhD thesis presented at Liege University, 2003.

[8] DEMONCEAU J.-F., JASPART J.-P., "Development of membranar effects in frame beams: experimental and analytical investigations", EUROSTEEL 2008, $5^{\text {th }}$ International conference on Steel and Composite Structures, 2008, pp. 1743-148

[9] LUU H.N.N., DEMONCEAU J.-F, JAPSART J.-P., "Global structural behaviour of a building frame further to its partial destruction by column loss", EUROSTEEL 2008 5th International conference on Steel and Composite Structures, 2008, pp. 1749-1754.

[10] DEMONCEAU J.-F., JASPART J.-P., "Experimental test simulating a column loss in a composite frame", International Journal of Advanced Steel Construction (IJASC), Vol. 6, No. 3, pp. 891-913.

[11] COMELIAU L., DEMONCEAU J.-F., JASPART J.-P., "Robustness of steel and composite buildings under impact loading", Proceedings of SDSS' Rio 2010 International Colloquium Stability and Ductility of Steel Structures, Vol. 1, 2010, pp. 393-400.

[12] COMELIAU L., DEMONCEAU J.-F., JASPART J.-P., "Robustness of building frames further to a column loss - Substructure approach with account of dynamic effects", EUROSTEEL 2011, 2011.

[13] SIMOES DA SILVA L., "Towards a consistent design approach for steel joints under generalized loading", Journal of Constructional Steel Research, JCSR Special Issue "Imperial College Centenary - Utilisation of experimental data in steel Structures Research". 